\title{
Liquidatie van een Solid Soldier?
}

\author{
Het 'niet-zeker-weten' en de 'realness' rondom de dood van \\ Sin
}

R.A. Roks*

30-jarige man komt om bij schietpartij Amsterdam-Zuidoost

\begin{abstract}
De man die maandagnacht tijdens een schietpartij in Amsterdam-Zuidoost ernstig gewond raakte, is inmiddels aan zijn verwondingen bezweken. Dat meldt de politie. Het incident gebeurde iets na 01.00 uur op een parkeerplaats aan de Wethouder Serrurierstraat. De politie maakte maandagochtend bekend dat het slachtoffer meerdere keren is geraakt. Vlak na het incident is de man overgebracht naar het ziekenhuis, waar hij uiteindelijk overleed. Over de toedracht van de schietpartij is vooralsnog niets bekend. De politie heeft na het incident wel geruime tijd onderzoek gedaan op de parkeerplaats. (Het Parool 20 augustus 2012)
\end{abstract}

In de nacht van zondag 19 op maandag 20 augustus 2012 wordt Quincy Soetosenojo in zijn woonplaats Amsterdam van dichtbij met meerdere kogels beschoten. Later die nacht bezwijkt hij in het ziekenhuis aan zijn verwondingen. Tijdens een etnografisch onderzoek naar de Haagse Rollin 200 Crips (Roks 2016a, 2016b) heb ik Sin, zoals hij door mijn respondenten werd genoemd, vooral leren kennen door de verhalen die er over hem verteld werden. Vanwege zijn nietsontziende manier van opereren op straat genoot hij onder leden van de Rollin 200 Crips veel aanzien. In de loop der jaren heb ik Sin verschillende keren meegemaakt in de nabijheid van de Crips, maar bleef het bij een begroeting en het wisselen van enkele woorden.

Omdat er vijf jaar na dato nog geen verdachte is opgepakt, kunnen geen uitspraken gedaan worden over de motieven of beweegredenen die ten grondslag lagen aan de aanslag op het leven van Sin. Om die

* Dr. Robby Roks is als universitair docent verbonden aan de sectie Criminologie van de Erasmus Universiteit Rotterdam. 
reden maak ik in deze bijdrage gebruik van een vergelijkbaar paradigmatisch vertrekpunt als Mattijs van de Port in zijn studie Geliquideerd (2001). Het beeld dat zich volgens Van de Port opdringt na het bestuderen van 55 politiedossiers over liquidaties ${ }^{1}$ is dat 'het niet-zekerweten rond een moordzaak een vacuüm creëert, een witte vlek die door alle betrokkenen wordt afgedekt met geruchten, vermoedens, gissingen, aannames, stereotyperingen, fantasieën, hypotheses, theorieën en ervaringskennis' (Van de Port 2001, p. 46). Van de Port stelt dat dit 'niet-zeker-weten' een imaginaire ruimte vormt die, in een gezamenlijk proces door criminologen, politie en justitie, de media en misdadigers, wordt vervangen door gepostuleerde stelligheden over het wezen van 'de onderwereld', de aard van haar bewoners en de rol van geweld (p. 55).

De dood van Sin bracht tijdens mijn veldwerk een vergelijkbaar 'nietzeker-weten' aan het licht, in het bijzonder ten aanzien van de motieven en achtergronden van de aanslag op zijn leven. In plaats van het belichten van het perspectief van politie en justitie - zoals in de analyse van Van de Port (2001) - staat in deze bijdrage centraal hoe de dood van Sin door de Rollin 200 Crips werd beleefd, geïnterpreteerd, en hoe zij aan dit gewelddadige incident betekenis gaven. In de media werden er verschillende (on) bewuste verklaringen aangereikt, motieven gepresenteerd en diverse verbanden gesuggereerd. Met deze openbare informatie zal worden begonnen om een beeld te schetsen van Sin en de manier waarop hij om het leven kwam.

\section{‘Een jongen die niet met zich laat spotten’}

'Het leek een afrekening binnen het criminele circuit, maar is dat wel zo?' is de vraag die presentatrice Anniko van Santen opwerpt aan het begin van het item over de dood van Sin in het bekende televisieprogramma Opsporing Verzocht op dinsdag 18 september 2012. In een recent verschenen verkennende voorstudie over liquidaties in Nederland stelt Van Gestel (2017, p. 13) dat er in de criminologische context doorgaans gebruik gemaakt wordt van 'een afrekening in het criminele milieu' om het begrip liquidatie te definiëren. Breder is de definitie die

1 Zie Van de Port (2001, p. 11-55) voor een uitgebreide problematisering van de definitie van het begrip 'liquidatie', alsmede de methodologische haken en ogen rondom het meten en tellen van liquidaties. 
door de voormalige Centrale Recherche Informatiedienst gehanteerd wordt, waarbij het gaat over 'het in verband met (kennis omtrent) andere misdrijven volgens plan doden van een of meer personen teneinde de positie van de dader/opdrachtgever binnen het criminele milieu te vestigen, te handhaven of te verstevigen' (Van Gestel 2017, p. 13). Zoals Van Gestel terecht opmerkt, vereist dit dat er meer bekend moet zijn over de achtergronden van het gewelddadige voorval. In het geval van Sin ontbreekt dergelijke openbare informatie, maar uit een krantenbericht in Spits (22 februari 2013) blijkt dat de recherche wel degelijk in een dergelijke richting denkt:

'De recherche is ervan overtuigd dat Quincy Soetosenojo vrijwel zeker het slachtoffer van een liquidatie moet zijn geweest. Het is duidelijk dat hij werd opgewacht en dat er doelgericht op hem is geschoten. Er ging in ieder geval geen ruzie aan vooraf. Hoewel hij nog kort leefde, heeft het slachtoffer zelf niets meer over de moordaanslag kunnen zeggen.'

(Spits 22 februari 2013)

Omdat er tot op heden geen verdachte(n) is/zijn aangehouden, blijft het onduidelijk wat de concrete motieven van de aanslag op het leven van Sin waren. De modus operandi van de aanslag sterkt echter het vermoeden dat het hier een liquidatie betreft.

Ondanks deze onduidelijkheid over de achtergronden of omstandigheden van de dodelijke schietpartij bevat de mediaberichtgeving over de dood van Sin meerdere voorbeelden die de suggestie wekken dat er sprake zou zijn van een 'criminele afrekening'. Het voorbehoud van Anniko van Santen of er wel gesproken kan worden van een afrekening, dreigt naar de achtergrond te verdwijnen wanneer in het vervolg van het item wordt belicht wat er over Sin bekend is bij de politie. Voice-over Frits Sissing stelt dat Sin zich zou hebben ontwikkeld tot 'een jongen die niet met zich laat spotten', onder andere omdat hij oprichter zou zijn van de Amsterdamse afdeling van de Crips en een 'aspirant-lid van de veelbesproken motorclub Satudarah'. Bovendien zou Sin 'niet bang zijn, maar voor zijn eigen veiligheid wel altijd een wapen bij zich dragen'. Ten slotte wordt melding gemaakt van het feit dat Sin rapmuziek opneemt waarin 'hij zijn gangsta levensstijl verheerlijkt', maar waarin hij 'ook aangeeft dat zijn levensstijl hem uiteindelijk wel eens zijn leven zou kunnen kosten'. Dezelfde thema's rondom de persoon van Sin vallen in de geschreven pers te herken- 
nen. Sin wordt beschreven als (aspirant-)lid van Satudarah (Algemeen Dagblad 21 augustus 2012), 'bendelid' (De Telegraaf 21 augustus 2012) en 'gangsta-rapper' (Het Parool 21 augustus 2012) /'gangsterrapper' (de Volkskrant 29 augustus 2012).

Tot aan zijn dood wist ik niet dat Sin actief was als rapper. Wel wist ik dat hij, net als veel van mijn andere respondenten, enkele nummers had geschreven en opgenomen. Zo had ik van Sin eerder nummers gehoord met de Aso Bros, een groep vrienden uit de Amsterdamse buurt Gein, en met zijn inmiddels eveneens overleden neef Iron Mike als 'Solid Soldiers'. In de media werd de dood van Sin echter gekoppeld aan het feit dat hij zich bezighield met het maken van muziek. Het Parool (21 augustus 2012) was hier het meest expliciet in:

\begin{abstract}
'Zoals gangstarappers betaamt, bezong Sin Quin het straatleven in de Bijlmer en in Gein gevat in teksten die de talrijke pr-functionarissen van stadsdeel Zuidoost niet erg zullen aanstaan ("Handschoen aan, bivak, klaar voor de overval; om de hoek wordt alweer iemand neergeknald; zo'n leven in Zuidoost, voor ons is dit normaal"). Gisternacht op dat enigszins afgelegen parkeerterreintje werd de geweldscultuur waarmee Soetosenojo zo had gedweept, hem fataal. Het verhaal gaat dat de politie Soetosenojo's kogelwerende vest had afgepakt. Nu kijken agenten in hemdsmouwen op gepaste afstand toe.' (Het Parool 21 augustus 2012)
\end{abstract}

Gezien de muzikale historie van rap is het niet verwonderlijk dat er in de media dergelijke verbanden worden geopperd. ${ }^{2}$ De suggestie die er in de media wordt gelegd tussen de dood van Sin en de muziek die hij maakte, hoezeer deze ook getuigt van stereotiepe ideeën over zowel straatcultuur als rapmuziek, kan echter begrepen worden afgaande op de paar nummers die er van Sin online te vinden zijn. In 'Als Je Mij Ziet' uit 2010 - te vinden op YouTube met bijna 50.000 views - neemt Sin op ijzingwekkende wijze een voorschot op zijn eigen gewelddadige dood door te rappen: 'Zet je een hit op mij, schiet me dan van dichtbij (...). Ben niet bang voor de dood, zeker niet voor lood' (Roks 2013, p. 20).

2 De betekenis en invloed van de zogenoemde 'lyrical content' van rapteksten en hun expliciete verwijzingen naar criminaliteit en geweld zijn in de Verenigde Staten herhaaldelijk onderwerp van maatschappelijke discussies geweest (Rose 1994, p. 1-9; Van Gemert 2005). Ook in Nederland krijgt de (vermeende) relatie tussen rapmuziek en geweld om de zoveel tijd aandacht (Roks 2013, p. 14-17). 


\section{'Die foto irriteert me echt'}

Drie dagen nadat Sin is doodgeschoten, bezoek ik de buurt in Den Haag die de Rollin 200 Crips hun 'h200d'3 noemen. Het grootste deel van de avond gaat het over de dood van Sin, waarbij door de Rollin 200 Crips nadrukkelijk gezocht wordt naar motieven en achtergronden van het gewelddadige voorval, maar vooral ook wie de mogelijke dader(s) zou(den) (kunnen) zijn. De gedetailleerde wijze waarop dit gebeurde, vertoonde naar mijn idee een opmerkelijke gelijkenis met de manier waarop de recherche in dit soort zaken doorgaans te werk gaat: er werd nagegaan met wie Sin veel tijd doorbracht en met wie hij conflicten had. Omdat Sin zich bewoog in verschillende kringen en daardoor uiteenlopende loyaliteiten had, was vrijwel iedereen verdacht en deden diverse vermoedens en complotten de ronde.

Behalve het voeren van gesprekken met vrienden en bekenden van Sin, werden ook ooggetuigenverslagen in krantenberichten uitgeplozen. Bovendien werden op internet verschenen foto's van de plaats delict uitvoerig bestudeerd. Vanwege de opstelling van de geparkeerde auto's en de positie van de auto's ten opzichte van de woning van Sin kon de schutter volgens de aanwezigen niet anders dan een bekende van Sin zijn geweest: de plek waar de bloedsporen op de foto te vinden zijn, suggereert immers een andere, afwijkende looproute van de parkeerplaats naar zijn woning. Die avond - en de avonden daarna - werd de aanslag van Sin meermaals gereconstrueerd op basis van de manier waarop de auto's geparkeerd stonden, aangevuld met verhalen van vrienden en kennis en informatie uit de media. Een aantal leden lijkt in die dagen een obsessie te ontwikkelen met een specifieke auto en lege parkeerplaats. 'Die foto irriteert me echt', hoorde ik een van hen bij herhaling zeggen. Ook het (soort) wapen en de kogels waarmee Sin zou zijn doodgeschoten, zijn onderwerp van een levendige discussie. Meer kennis over het type vuurwapen, het kaliber en de kogels waardoor Sin om het leven is gekomen, zou de Rollin 200 Crips meer duidelijkheid geven over de dader(s).

Naast de emotionele weerslag, die in een mix van ongeloof, verdriet en woede bij de leden van Crips viel waar te nemen, vormde de dood van Sin ook een reden voor leider Keylow om de 'codes' die gelden binnen de gang nogmaals te benadrukken: 
'Daarom zeg ik altijd: laat weten waar je bent. Die shit kan je in leven houden homie. Laat me weten waar je bent, zeg wanneer je thuis bent. Het klinkt kinderachtig, maar die shit kan je wel in leven houden. Het klinkt fucked up, maar dit leert jonge homies wel. Dit is geen grap, die shit is serieus. Fucked up dat een homie als Sin het voorbeeld moet zijn.' (23 augustus 2012, veldwerknotitie)

Met deze opmerking biedt Keylow een inkijk in de dagelijkse gang van zaken van de Rollin 200 Crips, waarbij leden omwille van hun eigen veiligheid verplicht worden van zich te laten horen en te melden wanneer ze thuis zijn. Als Sin zich volgens Keylow aan deze code had gehouden, dan had hij nu misschien nog geleefd. De onduidelijkheid rondom de dood van Sin wordt hiermee afgedekt door het (Haagse) gangleven af te schilderen als een gemeenschap met duidelijke gedragsregels en -codes en eigen normen en waarden (Van de Port 2001, p. 48). Het zijn dergelijke klip-en-klare voorstellingen over de gang van zaken rondom liquidaties die er volgens Van de Port op wijzen dat 'we ons al volop bevinden in de imaginaire ruimte van het “niet-zeker-weten”' (Van de Port 2001, p. 191). Vergelijkbaar is het betoog van Copes e.a. (2013) - net als Jimerson en Oware (2006) - dat we hier niet te maken hebben met daadwerkelijke gedrags- of straatcodes. Het 'vertellen van dergelijke codes' (Wieder 1974), zoals Keylow in het bovenstaande citaat, moet volgens deze auteurs eerder worden gezien als voorbeelden waarmee betrokkenen proberen om betekenis te geven aan de wereld om hen heen en hun gedrag aan anderen uit te leggen en te verklaren. Tegelijkertijd vormt het een manier waarop identiteit(en) kan/kunnen worden geconstrueerd en gepresenteerd (vgl. Roks 2015, p. 423, 2016a, p. 112).

\section{'Voor je het weet geef je zijn killer een hand'}

Na mijn eerste bezoek aan de h200d na de dood van Sin schreef ik in mijn dagelijkse veldwerknotities dat achterdocht en wantrouwen - 'tekenen van angst' volgens Van de Port (2001, p. 109-119) - mij opvallen als de centrale thema's in de gesprekken tussen leden van de Rollin 200 Crips. In een verslag van journalist Saul van Stapele, die gezamenlijk met enkele leden van de Rollin 200 Crips de plek bezocht waar Sin werd doodgeschoten, komt dit eveneens naar voren: 


\begin{abstract}
“'Het is raar zonder hem te komen, hier", zegt Keylow. "Dit is zijn hood." Hij pakt een fles Parbo-bier en bindt er een blauwe bandana omheen die door de Crips als hun "vlag" wordt gezien. Hij bekijkt de massa bij de wake argwanend, zegt hij. “ledereen gaat je condoleren. Voor je het weet geef je zijn killer een hand."' (Van Stapele 2012)
\end{abstract}

In de dagen na de dood van Sin lijken de Rollin 200 Crips in een 'hidden state of emergency' (Van de Port 2001, p. 110) te verkeren. Waar uitklapbare messen tot de standaarduitrusting van de leden van de Crips behoren en menig respondent er bovendien prat op gaat 'altijd strapped'4 te zijn, neemt de (persoonlijke) bewapening in de periode na de dood van Sin toe. Bovendien werd er in deze periode aan het begin van elke avond een wapen - variërend van een honkbalknuppel tot een klein vuurwapen - begraven in de aarde van een perkje in de buurt. Daarnaast leek het alsof de Crips meer dan ooit letten op onbekende personen. Toevallige passanten, zich van geen kwaad bewust, worden in de gaten gehouden, korte tijd gevolgd en een enkele keer gesommeerd om hun handen uit hun zakken te halen.

Een week na de aanslag op Sin wordt op zondag na de wekelijkse, min of meer verplichte training in een bos aan de rand van Den Haag het merendeel van de actieve leden naar de buurt gehaald voor een vergadering in een bos aan de rand van Zoetermeer. Voor vertrek wordt iedereen verplicht zijn telefoon uit te schakelen en de batterij te verwijderen. Aan een waterrand diep in het bos wordt een halve kring gevormd rondom enkele bankjes met Keylow als het letterlijke en figuurlijke middelpunt van de bespreking. Hij begint de vergadering met 'een minuut stilte voor de overleden homie'. Na de stilte vraagt hij de aanwezigen hoe ze zich voelen. Omdat er in eerste instantie geen reactie komt, stelt hij dezelfde vraag nog een keer. 'Boos', 'fucked up' en 'it's dark over here, cuzz' wordt er door een aantal Crips uitgebracht. Vervolgens deelt Keylow anderhalf uur lang zijn vermoedens en verdenkingen. Het valt mij op dat de aanwezige leden van de Crips tijdens de vergadering erg op hun hoede lijken. Constant, bijna op het schichtige af, kijken ze om zich heen. Overvliegende helikopters worden angstvallig gevolgd. Wanneer een man aan de andere kant van het water foto's aan het nemen is en er flitsen van de camera zichtbaar zijn, wordt gedacht dat zij door politie gefotografeerd worden. $\mathrm{Na}$

4 'Strapped' is Amerikaanse slang en deze term wordt door de leden van de Rollin 200 Crips gebruikt om aan te geven dat ze een wapen dragen. 
anderhalf uur stelt Keylow dat er teruggegaan moet worden naar de 'h200d', omdat de politie het anders verdacht zou kunnen vinden dat niemand van de Crips in de buurt aanwezig is. Als er op de parkeerplaats bij het bos twee mannen in een stilstaande auto zitten, wordt direct gefluisterd dat het politie is. Een van de oudere leden, met wie ik naar het bos ben meegereden, zet hierop zijn auto in zijn achteruit en rijdt, in plaats van richting de uitgang van de parkeerplaats, in de richting van de auto. Hij brengt zijn wagen tot stilstand voor de geparkeerde auto en kijkt de mannen ongeveer tien seconden indringend aan. Hierna rijdt hij weg. Omdat de inzittenden volgens hem 'paniekerig' keken, is hij ervan overtuigd dat ze niet van de politie zijn.

Op 29 augustus 2012 wordt Sin begraven in Amsterdam. Als ik voor het middaguur in de buurt aankom, schijnt de zon al flink en lijkt het een warme dag te worden. Marvin, een van de leden die al sinds halverwege de jaren negentig onderdeel uitmaakt van de Crips, is als eerste aanwezig. Na een korte begroeting vraagt hij of het mij opvalt dat hij een wapen onder zijn kleding draagt. Hij twijfelt namelijk of hij zijn jas aan zal trekken, maar vanwege het goede weer denkt hij dat dit misschien extra verdacht is. Ik geef hem in alle eerlijkheid aan dat het mij niet was opgevallen dat hij gewapend is, onder andere vanwege het oversized witte T-shirt dat hij draagt. Na zijn vraag valt het wel op dat meerdere leden van de Crips grote, wijde kleding aanhebben en, ondanks het zomerse weer, een jas dragen.

Ook op twee andere momenten die dag word ik geconfronteerd met het wapenbezit van mijn respondenten. Als we in de auto zitten na de begrafenis, pakt een van de leden een plastic tas met daarin een oudere dvd-speler. Op de snelweg verwijdert hij met behulp van een schroevendraaier een aantal kleine schroeven en schuift hij de kap van het apparaat los. Uit zijn jaszak haalt hij een zwart vuurwapen ter grootte van een hand. Ik schrik en probeer de spanning weg te nemen door hem te manen voorzichtig te zijn, omdat hij mij anders beter op de begraafplaats achter had kunnen laten. Hij lacht om mijn opmerking en zegt: 'Roks, it's on safety man, don't worry.' Hij stopt het wapen in een korte, zwarte sportsok en probeert de kap van de dvdspeler er weer op te schuiven. Het wapen lijkt echter niet goed in het apparaat te passen en hij worstelt om enkele van de kleine schroeven vast te maken. Bij terugkomst in de buurt wordt met enkele blauwe kaarsen, flessen van het Surinaamse biermerk Parbo, de rouwkaart van Sin, een zonnebril, een blauwe en zwarte bandana en - korte tijd - 


\section{Altaar ter nagedachtenis aan Sin}

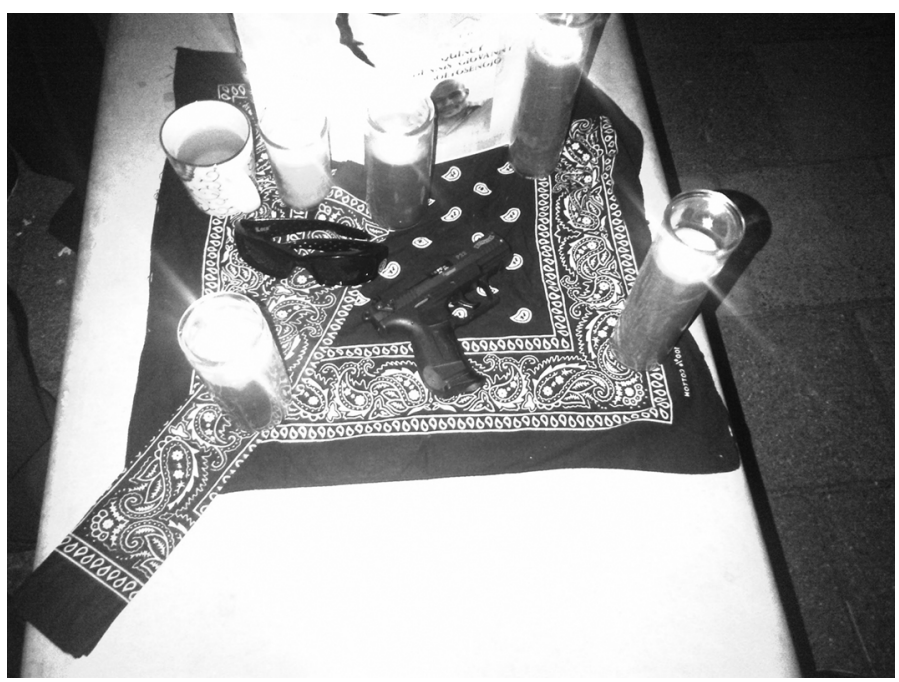

29 augustus 2012 (C) Robby Roks

een klein vuurwapen een soort altaar gemaakt. Voor het altaar worden in de loop van de avond meerdere (groeps)foto's ${ }^{5}$ genomen (afbeelding 1).

De dood van Sin, maar in het bijzonder het 'niet-zeker-weten' ten aanzien van de achtergronden van de aanslag op zijn leven, bood tijdens mijn veldwerk een kijk achter de schermen van de gewelddadige performances van de Haagse Crips. De mediapresentaties van de Crips bevatten meerdere voorbeelden waarin de suggestie wordt gewekt dat geweld aan de orde van de dag is. ${ }^{6}$ In de eerste scène van de documentaire Crips, Strapped 'n strong (2009) - symbolisch voor de gewapende en krachtige indruk die de Crips willen achterlaten - betreedt leider Keylow een woning waar de bloedsporen op de grond opgevoerd worden als de stille getuigen van een uit de hand gelopen ripdeal, en zegt hij:

5 Zie bijv. calohwagohmc.com/gallerycrips/wppaspec/oc1/Innl/cv0/ab3/pt21.

6 Een concreet voorbeeld vormt de trailer van de documentaire uit 2009 met de in dit opzicht betekenisvolle titel Crips, Strapped ' $n$ strong. Te bekijken via: www.youtube.com/ watch?v=VqPIgiY9Kx0, laatst bezocht op 17 juli 2017. 
'Kijk, het is denk ik duidelijk wat hier gebeurd is hè? Dit is een deal die fout is gegaan hè? En dit soort shit gebeurt elke dag en dit soort shit is wat mensen niet zien.'

Naast de bekendheid met geweld, wekken de Crips daarbij in de media op tijden de indruk dat zij een zekere mate van controle ervaren over het gebruik van geweld. In een interview met Panorama liet Keylow in 1994 optekenen:

'[A]ls ik wil dat je morgen dood bent, dan ben je morgen dood. Als ik wil dat je pas over een jaar aan de beurt bent, dan sterf je pas over een jaar.'

(Viering 1994, p. 41)

De nasleep van de dood van Sin gaf echter zicht op het feit dat geweld voor de Rollin 200 Crips op tijden, net als voor andere 'bewoners van de onderwereld' (Van de Port 2001, p. 120), een veel minder voorspelbaar karakter heeft.

\section{De 'realness' van de dood van Sin}

In de maanden na de begrafenis van Sin wordt de term 'real' een aantal maal nadrukkelijk gerelateerd aan zijn dood. Ongeveer twee weken na het overlijden van Sin lijkt een deel van de achterdocht en het wantrouwen, alhoewel er nog steeds op dagelijkse basis gespeculeerd wordt over de daders en het motief van de aanslag, bij de Rollin 200 Crips geleidelijk aan weg te ebben. Een aantal Crips lijkt niet of nauwelijks meer te reageren op onbekende passanten of langsrijdende scooters in de buurt. In tegenstelling tot de alertheid die ze in de weken daarvoor tentoonspreidden, hangen ze nu onderuitgezakt tegen het stalen hekwerk in de buurt. Ze praten hardop, lachen, roken en luisteren ondertussen naar muziek die uit de speaker van een mobiele telefoon komt. Dit alles tot ergernis van leider Keylow, die hun toeschreeuwt: 'De homie is dood man, keep it real alsjeblieft!' De 
gewelddadige dood van Sin wordt daarbij ingezet om de jongere leden ${ }^{7}$ te disciplineren om zich overeenkomstig het beeld van een 'echte' gang te gedragen.

De vraag wat er in deze specifieke context beschouwd moet worden als 'real', is echter niet eenvoudig te beantwoorden. In Real gangstas (2012, p. 77) wijst Lauger op een zogenaamde dilution narrative: 'a collective, though fragmented attempt by those invested in street life and street gangs to ascribe meaning to various collectivities that inhabit their surroundings'. Omdat veel jongeren in de stedelijke context het straat- en gangleven hebben omarmd, dreigt de manier waarop zij hier invulling aan geven steeds meer verwijderd te raken van de 'pure', 'originele', 'ideale' of 'echte' voorbeelden. Dat geldt in Indianapolis, waar Lauger zijn onderzoek deed en waar gesproken kan worden van een 'intergang environment' (Lauger 2012, p. 3-5), maar misschien nog wel nadrukkelijker in (Europese) landen, waar het beeld van wat er beschouwd moet worden als een 'echte' gang vooral ingegeven wordt door de stereotiepe beeldvorming over gangs in de populaire cultuur (Ferrell e.a. 2008, p. 129). Het originele beeld en de verbeelding zijn in dat laatste geval op een dergelijk complexe manier verstrengeld geraakt - waarvan de casus van de Rollin 200 Crips een goed voorbeeld is (Van Gemert e.a. 2016) - dat het onderscheid tussen 'real' en 'fake' eigenlijk niet langer valt te maken. Toch zijn dit termen die op straat in Nederland, en niet alleen door de Rollin 200 Crips, gebruikt worden als 'boundary work' (Lauger 2012, p. 99).

De 'realness' van de dood van Sin werd ook gebruikt om te verklaren waarom er in korte tijd veranderingen plaatsvonden in de samenstelling van de gang. Alhoewel alle leden onder de indruk waren van de gewelddadige dood van Sin, kwam dit op verschillende manieren tot uitdrukking. Oudere Crips benadrukten richting mij, maar ook richting jongere leden, dat zij de nodige ervaring hadden met vrienden die door geweld om het leven waren gekomen. Een enkeling gaf expliciet aan dat hij het 'gewend' was, of dat de dood van Sin hem dermate rauw op zijn dak viel dat hij nachtenlang niet kon slapen en regelmatig

7 In mijn proefschrift maak ik een onderscheid tussen de verschillende generaties Crips. Allereerst zijn er de 'Crips van het eerste uur', die sinds eind jaren tachtig/begin jaren negentig onderdeel uitmaken van de gang en zijn opgegroeid in of rondom de buurt die de Crips zien als hun uitvalsbasis. De leeftijd van deze leden ligt rond de 40 jaar. De tweede generatie Crips, waartoe ik Sin reken, is via leden van het eerste uur bij de Crips terechtgekomen. Deze leden variëren in leeftijd van rond de 20 tot begin 30 (Roks 2016a, p. 38-44). 
moest huilen. In de maanden na de dood van Sin vallen er in toenemende mate conflicten waar te nemen tussen leden van de Crips, die er uiteindelijk in resulteren dat meerdere jongere leden afstand nemen van de Rollin 200 Crips. Bij de nog actieve leden wordt hun vertrek nadrukkelijk gekoppeld aan de dood van Sin. Rick, een van de Crips van het eerste uur, zegt bijvoorbeeld:

'Zo gaat dat eigenlijk altijd. Eigenlijk na ... Eigenlijk na Sin, dan wordt het te real. Dan moeten ze opeens allemaal zogenaamd werken. Maar politie weet dat ook hè, daarom hebben ze het altijd over de harde kern.'

(20 december 2012, gesprek met Rick)

In een overzicht van wetenschappelijk onderzoek naar gangs, extremistische en radicale groeperingen laat Harris (2015, p. 45-46) zien dat de confrontatie met geweld een van de redenen vormt waarom mensen afstand (willen) nemen van dergelijke groepen. Met de vertrokken leden spreek ik uitvoerig over hun ervaringen als onderdeel van de Crips. Het merendeel is teleurgesteld over de dagelijkse gang van zaken en het gebrek aan financiële vooruitgang (Roks 2016a, p. 227249). Geen van hen wijst in de persoonlijke en soms emotionele gesprekken die we voeren echter expliciet op de rol van de dood van Sin in hun beslissing om de Crips de rug toe te keren. ${ }^{8}$

Sinds de Rollin 200 Crips met enige regelmaat in de media verschijnen, valt hun de nodige scepsis ten deel ten aanzien van de (gewelddadige) manier waarop zij zich als Nederlandse 'gang' presenteren. In de media, maar ook tijdens mijn veldwerk, vormde geweld steevast het antwoord op vermeende twijfels over de geloofwaardigheid of authenticiteit van uitspraken over het 'gangleven' in Nederland. Tijdens een aflevering van Moccah op televisiezender The Box in 2005 zegt Keylow:

'Weet je, ik bedoel, je hoort veel mensen zeggen dit Amerika nadoen, dat Amerika nadoen, maar Europese kogels maken ook mensen dood.'

Geweld heeft in dit geval een transformative magic en kan comic-book symbolism tot leven brengen (Katz 1988, p. 129-131; Van Hellemont 2015, p. 191-224). Ook van de dood van Sin ging een dergelijke overstijgende 'realness' uit. In de periode na de dood van Sin werd duide-

8 Daarmee is overigens niet gezegd dat dit gewelddadige voorval geen rol van betekenis heeft gespeeld in het verlaten van de Rollin 200 Crips. 
lijk hoe belangrijk hij was voor de leden van de Rollin 200 Crips en hoeveel status en respect hij bij hen had opgebouwd. Op sociale media valt geregeld te lezen dat er aan Sin gedacht wordt ('R.I.P. Sin nogsteeds \#ektesoldaat' - 6 augustus 2013, 16:18) en wordt zijn dood jaarlijks herdacht. De website van Caloh Wagoh Main Triad MC, een recent opgerichte outlaw motorcycle gang waar enkele prominente leden van de Rollin 200 Crips deel van uitmaken, bevat een pagina die is opgedragen aan alle 'cuzzo's die we door de jaren heen helaas zijn verloren. Zij zullen nooit worden vergeten.' Onder een foto van Sin staat het onderschrift 'Triad In Peace Sin Locc'. Ten slotte leeft de herinnering aan Sin ook voort in de namen van enkele zoons van mijn respondenten, die zijn vernoemd naar ofwel zijn wettelijke voornaam, ofwel zijn straatnaam.

\section{Tot besluit}

In deze bijdrage beschreef ik de manieren waarop de dood van Sin door de Rollin 200 Crips werd geïnterpreteerd en hoe zij hier betekenis aan gaven. Rondom de dood van Sin vallen verschillende 'narratives as interpretation' (Presser 2009, p. 182; Presser \& Sandberg 2015) te herkennen. Aan de ene kant geven de post-factumspeculaties en -geruchten, maar ook het benadrukken van straatcodes, zicht op het 'nietzeker-weten' ten aanzien van de achtergronden van de gewelddadige dood van Sin. De achterdocht en argwaan, alsmede de tijdelijk toegenomen (persoonlijke) bewapening, tonen dat de Rollin 200 Crips, anders dan de instrumentele logica die geweld tijdens mijn veldwerk of in de mediapresentaties soms toegedicht kreeg, zich geconfronteerd zagen met het grillige karakter van geweld op straat.

Naast de onzekerheid van het 'niet-zeker-weten' produceerde de dood van Sin een aantal narratieven over de 'realness' van het Haagse straatleven. Volgens een deel van mijn respondenten - voornamelijk de Crips van het eerste uur - lag de dood van Sin aan de basis van het vertrek van meerdere (jongere) leden in korte tijd. Hierbij werd een onderscheid gemaakt tussen de Crips die 'real' bleken en bleven en de 'fake' leden die uiteindelijk niet geschikt bleken voor de harde realiteit van het Haagse gangleven. De vertrokken leden gaven echter andere redenen voor het verlaten van de Crips en brachten dit niet (direct) in verband met de dood van Sin. Door jong en oud, zowel de actieve als 
de vertrokken Crips, werd Sin gezien als 'real' en genoot hij bijzonder veel respect. Deze 'realness' maakt dat Sin tot lang na zijn dood herinnerd zal worden. De dood van Sin, en de verhalen die verteld zullen worden over zijn persoon en de omstandigheden waaronder hij het leven liet, kan ten slotte worden geïnterpreteerd als een bevestiging van de gewelddadige context waarin de Rollin 200 Crips zich begeven (Roks 2016a, p. 185). Om deze redenen vertegenwoordigt de dood van Sin een indrukwekkend en betekenisvol moment tijdens mijn veldwerk en, meer in het algemeen, in de geschiedenis van de Haagse Rollin 200 Crips.

\section{Literatuur}

\section{Copes e.a. 2013}

H. Copes, F. Brookman \&

A. Brown, 'Accounting for violations of the convict code', Deviant Behavior (34) 2013, afl. 10, p. 841-858.

\section{Ferrell e.a. 2008}

J. Ferrell, K. Hayward \& J. Young, Cultural criminology: An invitation, Newbury Park: Sage 2008.

\section{Van Gemert 2005}

F.H.M. van Gemert, 'Gangsta rap; de controverse voorbij', Justitiële verkenningen (31) 2005, afl. 4, p. 68-82.

\section{Van Gemert 2012}

F.H.M. van Gemert, 'De Pose; boevenbiografie tussen structuur en interactie', Tijdschrift over Cultuur en Criminaliteit (2) 2012, afl. 3, p. 17-32.

\section{Van Gemert e.a. 2016}

F.H.M. van Gemert, R.A. Roks \& M. Drogt, 'Dutch Crips run dry in liquid society', in: C. Maxson \& F. Esbensen (red.), Gang transitions and transformations in an international context, New York: Springer International Publishing 2016.

\section{Van Gestel 2017}

B. van Gestel m.m.v. M.A. Verhoeven, Verkennende voorstudie liquidaties (Cahier 2017-7). Den Haag: WODC 2017.

\section{Harris 2015}

K.J. Harris, Leaving ideological social groups behind: A grounded theory of psychological disengagement, Edith Cowan University Western Australia, Faculty of Health, Engineering and Science 2015. 


\section{Van Hellemont 2015}

E. van Hellemont, The gang game: The myth and seduction of gangs (diss. Leuven), 2015.

\section{Jimerson \& Oware 2006}

J.B. Jimerson \& M.K. Oware, 'Telling the code of the street. An ethnomethodological ethnography', Journal of Contemporary Ethnography (35) 2006, afl. 1, p. 24-50.

\section{Katz 1988}

J. Katz, Seductions of crime. Moral and sensual attractions in doing evil, New York, NY: Basic Books 1988.

\section{Lauger 2012}

T. Lauger, Real gangstas: Legitimacy, reputation, and violence in the intergang environment, New Brunswick: Rutgers University Press 2012.

\section{Van de Port 2001}

M. van de Port, Geliquideerd; criminele afrekeningen in Nederland, Amsterdam: Meulenhoff 2001.

\section{Presser 2009}

L. Presser, 'The narratives of offenders', Theoretical Criminology 2009, afl. 2, p. 177-200.

\section{Presser \& Sandberg 2015}

L. Presser \& S. Sandberg, Narrative criminology: Understanding stories of crime, New York: New York University Press 2015.

\section{Roks 2013}

R.A. Roks, 'De straat praat? De performance van "street credibility”, Tijdschrift over Cultuur en Criminaliteit (3) 2013, afl. 3, p. 14-31.

\section{Roks 2015}

R.A. Roks, “"Never snitch broertje, want de straat hoort het"', Ars Aequi (64) 2015, afl. 5, p. 422-425.

\section{Roks 2016a}

R.A. Roks, In de h200d. Een eigentijdse etnografie over de inbedding van criminaliteit en identiteit, Rotterdam: Erasmus Universiteit Rotterdam 2016.

\section{Roks 2016b}

R.A. Roks, 'In de h200d. Een eigentijdse etnografie', Justitiële verkenningen (42) 2016, afl. 1, p. 47-64.

\section{Rose 1994}

T. Rose, Black noise: Rap music and black culture in contemporary America, Londen: University Press of New England 1994.

\section{Van Stapele 2012}

S. van Stapele, 'Deze Crip sliep al jaren "heel lichtjes”, $N R C 21$ augustus 2012.

\section{Viering 1994}

P. Viering, 'Straatroof, inbraak, doodslag', Panorama 1994, afl. 3, p. 37-42.

\section{Wieder 1974}

D.L. Wieder, Language and social reality: The case of telling the convict code, Den Haag: Mouton 1974. 